\title{
Effect of heat treatment on microstructure and properties of semi-solid squeeze casting AZ91D
}

\author{
*Zhi-yong You', Ao-xue Jiang', Zhuang-zheng Duan', Gang-ping Qiao', Jing-lei Gao², and Ling-bing Guo ${ }^{2}$ \\ 1. College of Materials Science and Engineering, Taiyuan University of Technology, Taiyuan 030024, China; \\ 2. Shanxi Huaxiang Group Co., Ltd, Linfen 011600, China
}

\begin{abstract}
Semi-solid AZ91D magnesium alloy billets were prepared by near-liquidus heat holding. Semi-solid squeeze casting was conducted at 575,585 and $595^{\circ} \mathrm{C}$, respectively, with $1 \mathrm{~mm} \cdot \mathrm{s}^{-1}$ squeeze speed. The semisolid squeeze casting AZ91D samples were heat treated by T4 (solution at $415^{\circ} \mathrm{C}$ for $24 \mathrm{~h}$ ) and T6 (solution at $415{ }^{\circ} \mathrm{C}$ for $24 \mathrm{~h}+220{ }^{\circ} \mathrm{C}$ for $8 \mathrm{~h}$ ) processes, respectively. The microstructure and mechanical properties of the alloy in different states were investigated by means of OM, SEM and tensile testing machine. The results show that compared to as-cast alloy, the grain size of the semi-solid squeezed AZ91D decreased significantly, and with the increase of semi-solid squeeze temperature, the grain size of AZ91D increased. The grains of the alloy were refined by T4 treatment, and further refined by T6 treatment. T6 treatment greatly improved the tensile strength, elongation, and hardness, but did not significantly improve yield strength. After $575{ }^{\circ} \mathrm{C}$ squeeze casting and T6 treatment, the ultimate tensile strength (UTS) reached $285 \mathrm{MPa}$, the elongation reached $13.36 \%$, and the hardness also reached the maximum (106.8 HV), but the yield strength (YS) was only $180 \mathrm{MPa}$. During the process of semi-solid squeeze casting and heat treatment, the matrix grain was refined and a large number of precipitated and secondary precipitated phases of $\mathrm{Mg}_{17} \mathrm{Al}_{12}$ appeared. Both the average size of matrix grain and secondary precipitated phase decreased, while the volume fraction of secondary precipitated phase increased. All these resulted in high tensile strength, elongation and hardness.
\end{abstract}

Key words: AZ91D; semi-solid squeeze casting; solution aging treatment; microstructure; mechanical properties. CLC numbers: TG146.22 Document code: A

Article ID: 1672-6421(2020)03-219-08

$\mathrm{M}$ agnesium alloys have attracted considerable attention due to their low density and light weight, and are widely used in aerospace, automobile, electronic communications and other industries. However, weak comprehensive mechanical properties limit their application. AZ91D is a representative magnesium alloy with a wide semi-solid temperature range and good casting capability ${ }^{[1]}$. Researchers have tried many methods such as hot extrusion, and semi-solid squeeze casting to further improve the comprehensive mechanical properties of AZ91D magnesium alloy, and they achieved good results. Wang Xiaojun et al. ${ }^{[2]}$ found that the mechanical properties of AZ91 magnesium alloy were greatly improved

\section{*Zhi-yong You}

Male, born in 1971. Associate Professor. Research interests: magnesium and aluminum matrix composites, research and application of laser rapid manufacturing technology.

E-mail: youzhiy1486@163.com

Received: 2019-11-07; Accepted: 2020-04-06 by hot extrusion and $\mathrm{SiC}$ addition, with the ultimate compressive stress reaching $187.5 \mathrm{MPa}$. The research work of Chen Tian et al. ${ }^{[3]}$ showed that the semi-solid squeeze casting AZ61 alloy after partial remelting produced more ideal, finer semi-solid microstructure and better mechanical properties compared with as-cast AZ61 alloy treated by the same isothermal holding conditions. Kleiner $\mathrm{S}$ et al. ${ }^{[4]}$ investigated the magnesium-aluminium castings produced by means of semi-solid squeeze casting, and found that the microstructure and mechanical properties of the alloy are better than castings by semi-solid squeezing.

Semi-solid squeeze casting is an effective method to optimize microstructure and improve comprehensive mechanical properties of magnesium alloy. However, due to the existence of reticular eutectic phase in the microstructure, the mechanical properties of semi-solid squeeze cast magnesium alloy are lower than that of die castings ${ }^{[5]}$. Whereas, heat treatment can eliminate this reticular structure and then improve the mechanical properties of the alloy. Li Yuandong et al. ${ }^{[6]}$ studied the 
effect of solution and aging treatment on properties of semi-solid squeeze cast AZ91D, and found the peak hardness of the alloy reached $86 \mathrm{HB}$ with the optimal heat treatment temperature and time. Sun Xuefei et al. ${ }^{[7]}$ found that the maximum tensile strength of squeeze cast SiC/AZ91 alloy was greatly increased to $385 \mathrm{MPa}$ after aging treatment. Qi Yesi et al. ${ }^{[8]}$ studied the effect of solution time on microstructure and mechanical properties of thixoformed AZ63 magnesium alloy. The tensile strength and elongation reached the maximum values of $341 \mathrm{MPa}$ and $17.8 \%$, respectively, after solid solution at $430{ }^{\circ} \mathrm{C}$ for $12 \mathrm{~h}$.

In this study, AZ91D magnesium alloy was prepared with semi-solid squeeze casting, using a self-developed squeeze casting die. In order to optimize the microstructure and further improve the mechanical properties of the magnesium alloy, the semi-solid squeeze cast AZ91D magnesium alloy was subjected to T4 and T6 heat treatment. The effect of grain refinement and the precipitations on the mechanical properties was investigated by measuring the size and volume fraction of matrix grains and precipitations, according to tensile stressstrain curves and SEM micrographs. The research provided a feasible preparation method and theoretical basis for preparing high-performance magnesium alloy castings.

\section{Experimental procedure}

AZ91D magnesium alloy was heated to $740{ }^{\circ} \mathrm{C}$ until completely melted, then $0.4 \mathrm{wt} . \% \mathrm{Ca}$ was added as fireretardant. $0.1 \mathrm{wt} . \% \mathrm{C}_{2} \mathrm{Cl}_{6}$ was added as refining agent as the melt was cooled to $720{ }^{\circ} \mathrm{C}$, holding for $10 \mathrm{~min}$, and then the melt was further cooled to $596{ }^{\circ} \mathrm{C}$ and held for $30 \mathrm{~min}$. Finally, the melt was poured into the preheated copper mold at $200{ }^{\circ} \mathrm{C}$, held for $15 \mathrm{~s}$ and quickly cooled in water to obtain the semi-solid AZ91D magnesium alloy blanks. The semisolid AZ91D blanks, at temperatures of 575, 585 and $595{ }^{\circ} \mathrm{C}$, respectively, were squeezed on the self-developed semi-solid squeeze casting die (Fig. 1) on a 200 t press machine with an squeeze speed of $1 \mathrm{~mm} \cdot \mathrm{s}^{-1}$. The squeeze specimens were then heat treated at $415{ }^{\circ} \mathrm{C}$ for $24 \mathrm{~h}(\mathrm{~T} 4)$ and $415{ }^{\circ} \mathrm{C}$ for $24 \mathrm{~h}+$ $220{ }^{\circ} \mathrm{C}$ for $8 \mathrm{~h}$ (T6), respectively. Samples for microstructure observation and mechanical properties testing were taken from the bottom of the castings (as shown by the red arrow in Fig. 1). Table 1 lists the AZ91D samples (squeezed at different temperatures) under different heat treatment conditions.

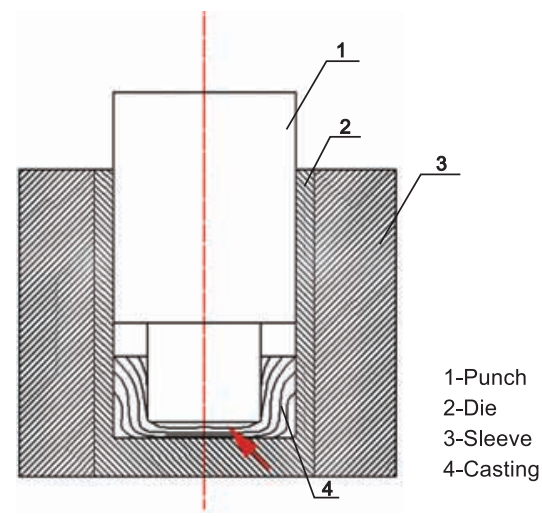

Fig. 1: Drawing of self-developed semi-solid squeeze die and casting

Table 1: Samples of AZ91D alloy in different states and squeeze temperatures

\begin{tabular}{cccccccccc} 
Sample No. & Y11 & T411 & T611 & Y12 & T412 & T612 & Y13 & T413 & T613 \\
$\begin{array}{c}\text { State } \\
\begin{array}{c}\text { Squeeze } \\
\text { temperature }\end{array}\end{array}$ & As-squeezed & T4 & T6 & As-squeezed & T4 & T6 & As-squeezed & T4 & T6 \\
\hline
\end{tabular}

A Leica $6000 \mathrm{M}$ optical microscope (OM) and a Tescan scanning electron microscope (SEM) were used for microstructure observations. The samples were etched by $4 \%$ nitric acid and alcohol. The phase constitution of the samples was analyzed using the Bruker D8ADVANCE X-ray diffractometer (XRD). The grain sizes were measured using ImagePro Plus 5.0 software. The tensile properties of the specimens were tested using a universal tensile tester under a tensile speed of $0.5 \mathrm{~mm} \cdot \mathrm{s}^{-1}$. The hardness of AZ91D was tested using HUAYIN Vickers hardness instrument under a loading force of $0.981 \mathrm{~N}$.

\section{Results and discussion}

\subsection{Microstructure}

Figure 2 shows the XRD results of AZ91D alloy squeezed at $575^{\circ} \mathrm{C}$, and after $\mathrm{T} 4$ and $\mathrm{T} 6$ treatment, which indicates that all the alloys in different states are composed of $\alpha-\mathrm{Mg}$ and the second phase $\mathrm{Mg}_{17} \mathrm{Al}_{12}$. Figure 3 shows the SEM micrograph and corresponding EDS surface scanning of AZ91D squeezed at $575{ }^{\circ} \mathrm{C}$ after $\mathrm{T} 6$ treatment. It can be seen that there are

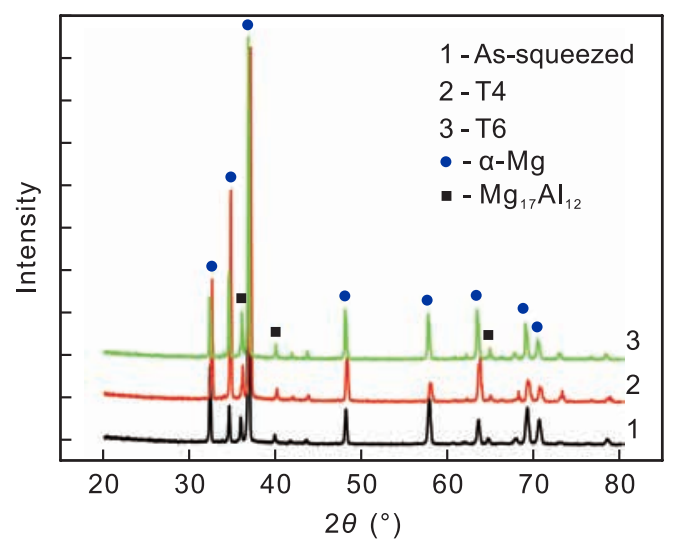

Fig. 2: XRD graph of AZ91D (squeezed at $575^{\circ} \mathrm{C}$ ) under different states 

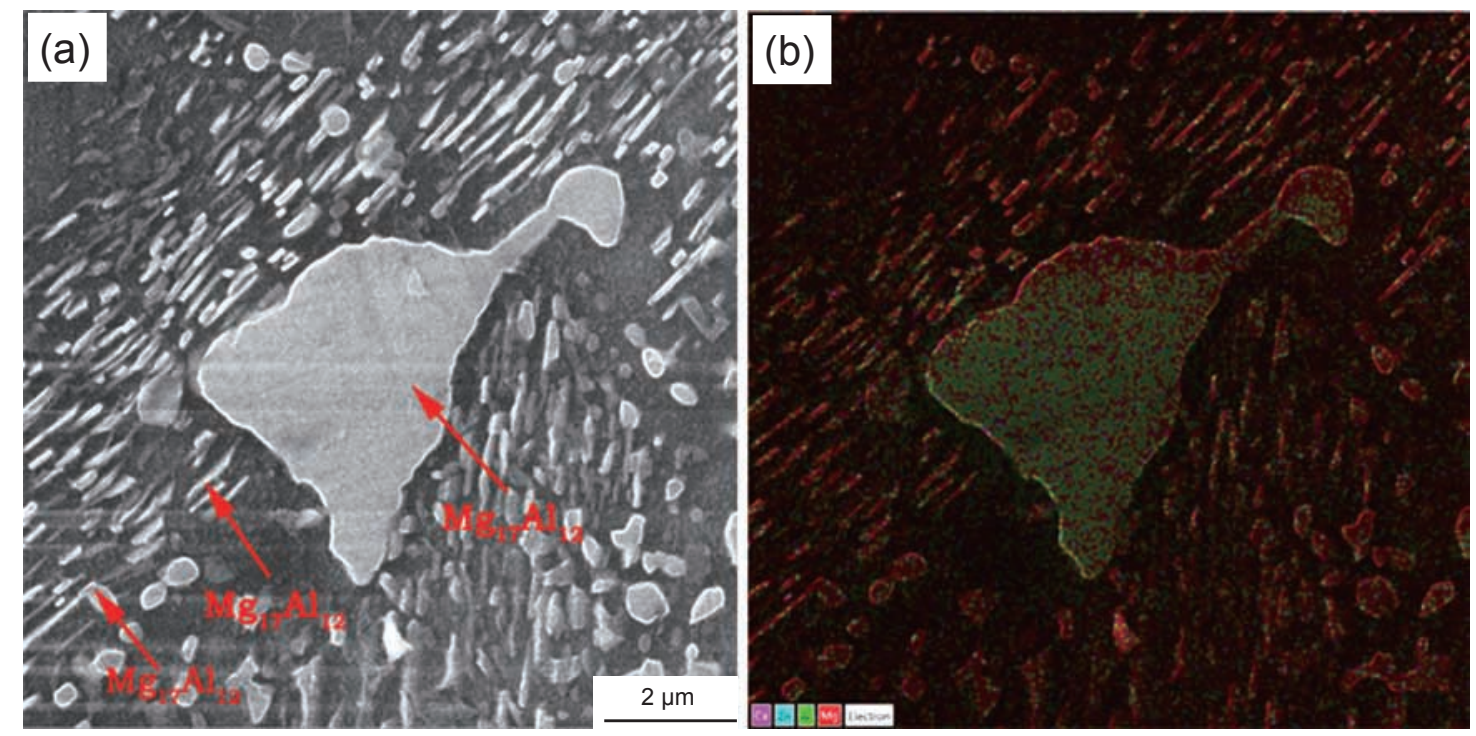

Fig. 3: SEM micrograph (a) and corresponding EDS surface scan (b) of AZ91D (squeezed at $575{ }^{\circ} \mathrm{C}$ ) after T6 treatment

point-like, lamellar and island-like $\mathrm{Mg}_{17} \mathrm{Al}_{12}$ second phases in this microstructure, and the island-like phase is surrounded by point-like and lamellar phases. Figure 4 shows the microstructure of AZ91D magnesium alloy in different states as the semi-solid squeeze temperature is $575^{\circ} \mathrm{C}$ (the lower left corner of each image is a partial enlargement). As shown in Fig. 4 (a), the grain of the as-cast microstructure is coarse, the island-like second phases $\mathrm{Mg}_{17} \mathrm{Al}_{12}$ (marked by $\mathrm{I}-\mathrm{Mg}_{17} \mathrm{Al}_{12}$ in Fig. 4) are distributed at the grain boundary, and uniformly surrounded by lamellar $\mathrm{Mg}_{17} \mathrm{Al}_{12}$ (marked by $\mathrm{L}-\mathrm{Mg}_{17} \mathrm{Al}_{12}$ in Fig. 4). Figure 4 (b) shows the microstructure of the semi-solid billet, in which the lamellar and point-like $\mathrm{Mg}_{17} \mathrm{Al}_{12}$ phases are completely dissolved in the matrix. Figure 4 (c) shows that after the semi-solid squeezing, the grains are squashed, and the point-like $\mathrm{Mg}_{17} \mathrm{Al}_{12}$ precipitates (marked by $\mathrm{P}-\mathrm{Mg}_{17} \mathrm{Al}_{12}$ in Fig. 4) are uniformly distributed at the grain boundaries. After T4 treatment [Fig. 4 (d)], the point-like precipitates redissolved in the matrix, however, a great number of secondary lamellar $\mathrm{Mg}_{17} \mathrm{Al}_{12}$ (marked by $2 \mathrm{~L}-\mathrm{Mg}_{17} \mathrm{Al}_{12}$ in Fig. 4) precipitate near the grain boundary and spread into the grain. After T6 treatment [Fig. 4 (e)], the lamellar secondary precipitates fill the whole grain, and then are gradually spheroidized.

Figure 5 shows the OM microstructure of AZ91D magnesium alloy at different squeezing temperatures and in different states. The grain size shows a continuous increase with the increasing squeezing temperature. After T4 and T6 treatment, the point-like

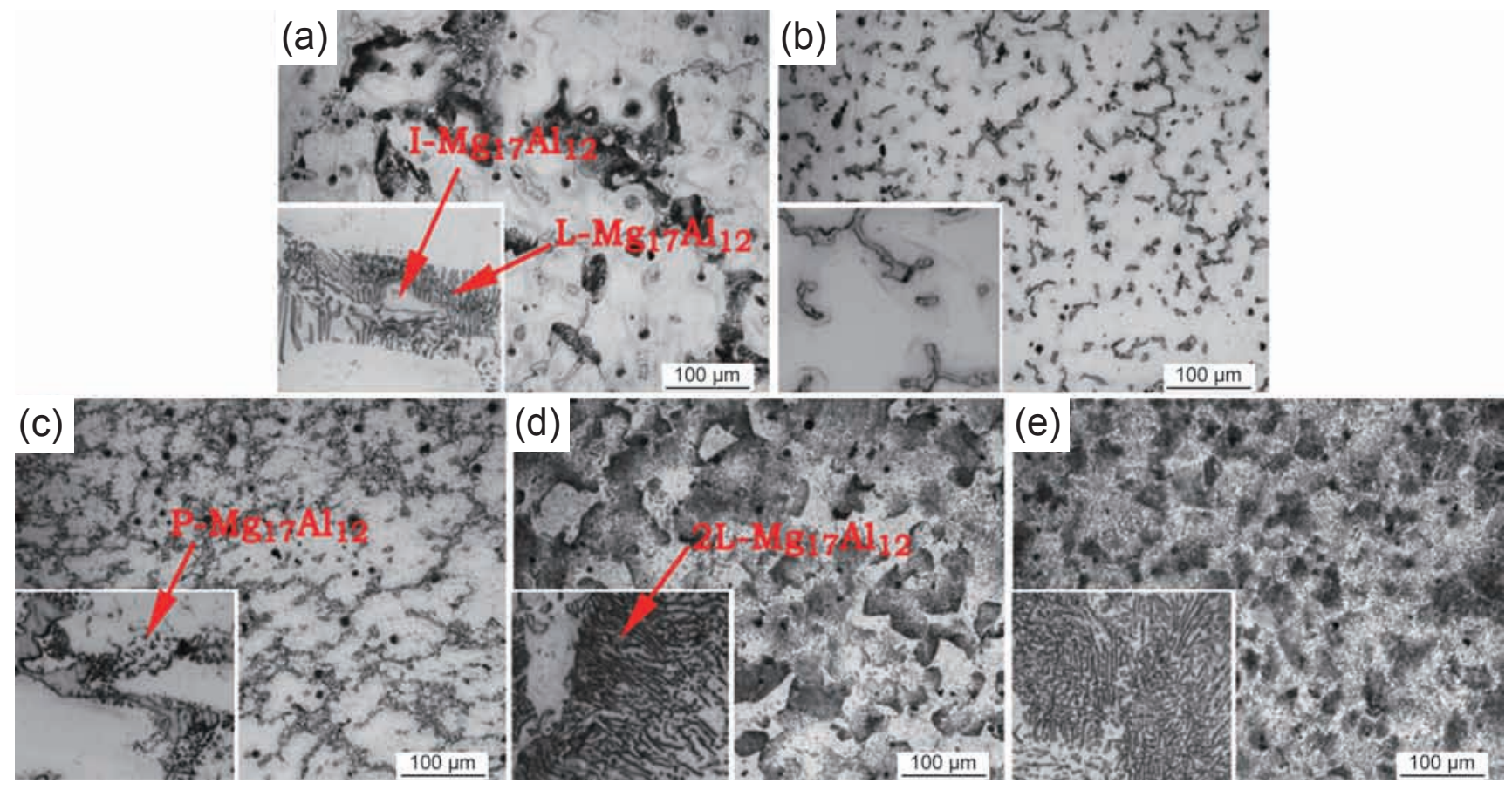

Fig. 4: OM microstructure of AZ91D in different states: (a) as-cast; (b) semi-solid; (c) squeezed at $575^{\circ} \mathrm{C}$; (d) $\mathrm{T} 4$ treated; (e) T6 treated 

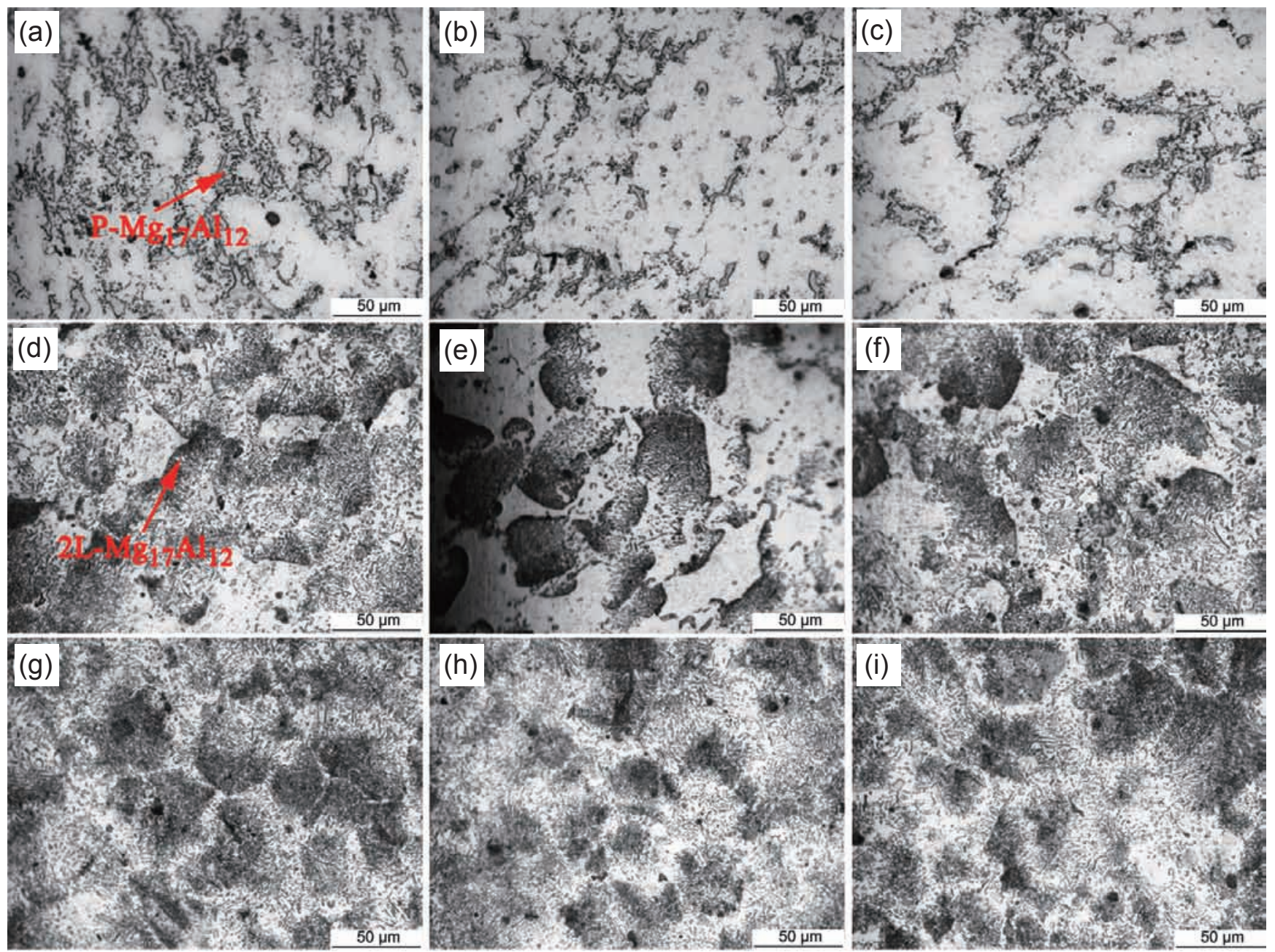

Fig. 5: OM microstructure of AZ91D squeezed at different temperatures: (a) Y11; (b) Y12; (c) Y13; (d) T411; (e) T412; (f) T413; (g) T611; (h) T612; (i) T613

phases at the grain boundary disappear, and a great number of lamellar secondary precipitations are found inside the grain. As heat treatment continued, the grains are refined and the lamellar $\mathrm{Mg}_{17} \mathrm{Al}_{12}$ phases are gradually spheroidized.

Figure 6 displays the grain size of AZ91D magnesium alloy samples in different states. As shown in Fig. 6, at the same squeeze temperature $\left(575{ }^{\circ} \mathrm{C}\right)$, the grain size continuously decreases after T4 and T6 treatment. The grain size decreases from 50-65 $\mu \mathrm{m}$ of as-squeezed to $20-35 \mu \mathrm{m}$ of T4 and 15$25 \mu \mathrm{m}$ of $\mathrm{T} 6$. When the squeeze temperature was $575{ }^{\circ} \mathrm{C}$, the average grain size after $\mathrm{T} 6$ heat treatment reached the

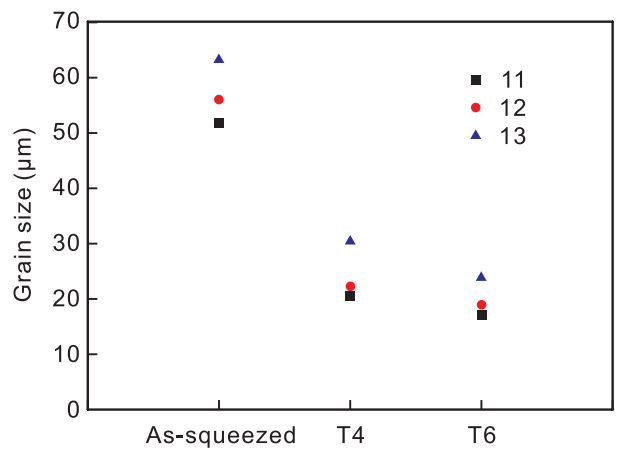

Fig. 6: Grain size of AZ91D in different states minimum $(17.01 \mu \mathrm{m})$.

Figure 7 shows the OM and SEM images of AZ9D magnesium alloy squeezed at $575{ }^{\circ} \mathrm{C}$. Figures 7 (a) and (d) show the presence of $\alpha-\mathrm{Mg}$, island-like $\mathrm{Mg}_{17} \mathrm{Al}_{12}\left(\mathrm{I}_{-}-\mathrm{Mg}_{17} \mathrm{Al}_{12}\right)$ and point-like $\mathrm{Mg}_{17} \mathrm{Al}_{12}\left(\mathrm{P}-\mathrm{Mg}_{17} \mathrm{Al}_{12}\right)$ in the alloy after semisolid squeeze casting. Figures 7(b) and (e) exhibit a great number of secondary lamellar $\mathrm{Mg}_{17} \mathrm{Al}_{12}\left(2 \mathrm{~L}-\mathrm{Mg}_{17} \mathrm{Al}_{12}\right)$ precipitates after $\mathrm{T} 4$, distributing from near the grain boundary to inside the grain. Only small numbers of $\mathrm{P}-\mathrm{Mg}_{17} \mathrm{Al}_{12}$ phases are observed at the boundary. Figures 7(c) and (f) show that the $2 \mathrm{~L}-\mathrm{Mg}_{17} \mathrm{Al}_{12}$ phases in the grain precipitate in large quantities until they cover the entire grain after $\mathrm{T} 6$, and gradually become spherical ( $\left.2 \mathrm{P}-\mathrm{Mg}_{17} \mathrm{Al}_{12}\right)$, but remain directional distribution.

Table 2 lists the size and volume fraction of $\mathrm{Mg}_{17} \mathrm{Al}_{12}$ in the alloy squeezed at different temperatures and at different states. After heat treatment, the size of the second phase decreased, while its volume fraction increased. After the $575{ }^{\circ} \mathrm{C}$ semisolid squeeze casting and T6 treatment, the size of second phase reached the minimum $0.50 \mu \mathrm{m}$, and its fraction reached $23.05 \%$.

During the semi-solid squeeze casting process, because the stacking fault energy (SFC) of $\mathrm{Mg}$ is low, the dislocation cross slips and climbs with difficulty, which increases the dislocation density and distortion energy ${ }^{[9]}$. Therefore, the 

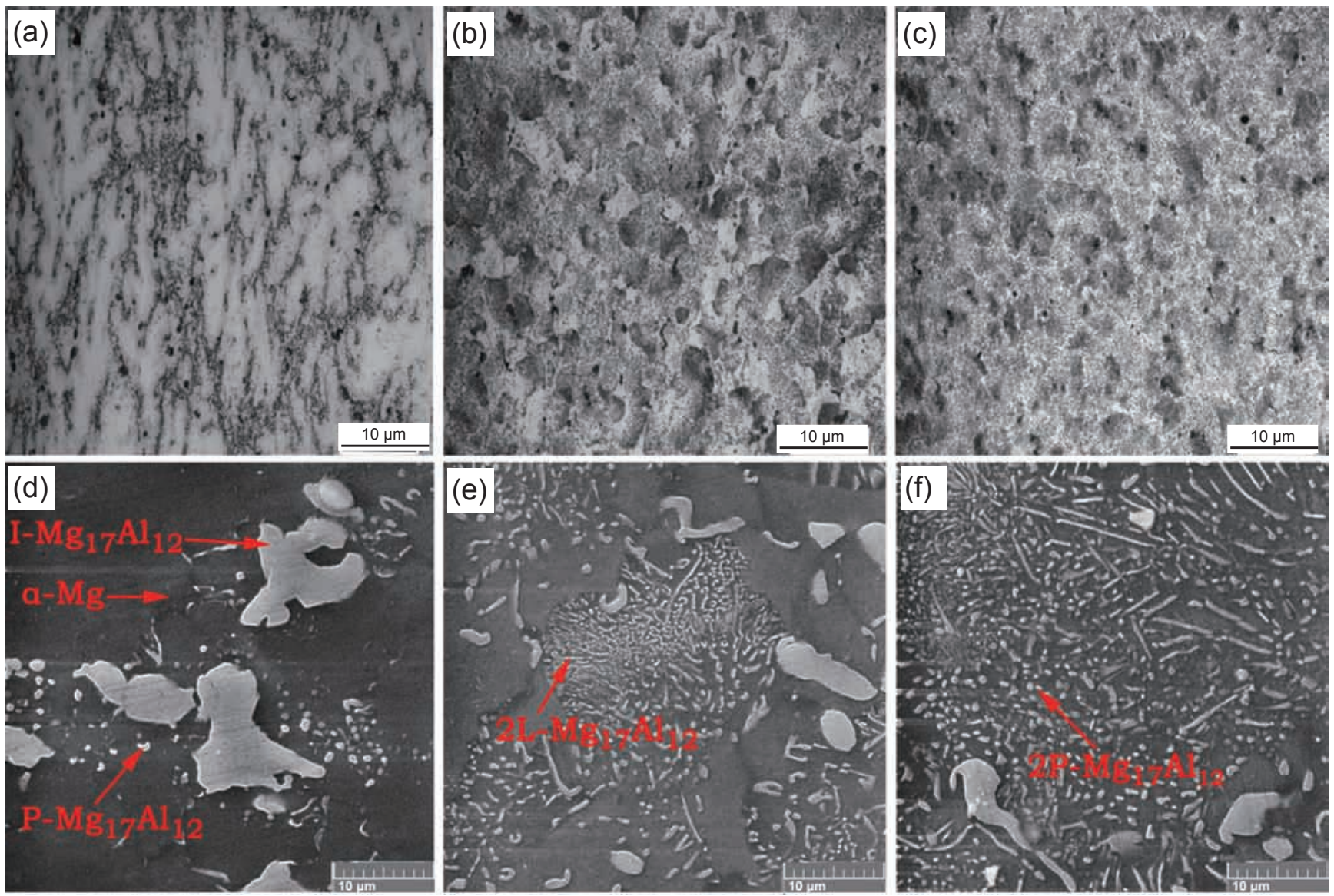

Fig. 7: OM, SEM images of AZ91D squeezed at $575^{\circ} \mathrm{C}$ : (a) and (d) Y11; (b) and (e) T411; (c) and (f) T611

Table 2: Size and volume fraction of $\mathrm{Mg}_{17} \mathrm{Al}_{12}$ phases at different states

\begin{tabular}{|cccccccccc}
\hline State & Y11 & T411 & T611 & Y12 & T412 & T612 & Y13 & T413 & T613 \\
\hline $\begin{array}{c}\text { Phase diameter } \\
(\mu \mathrm{m})\end{array}$ & 0.69 & 0.59 & 0.50 & 0.74 & 0.68 & 0.60 & 0.83 & 0.75 & 0.63 \\
$\begin{array}{c}\text { Phase volume fraction } \\
(\%)\end{array}$ & 8.15 & 17.14 & 23.05 & 8.90 & 18.06 & 23.54 & 11.87 & 19.82 & 23.91 \\
\hline
\end{tabular}

dynamic recrystallization easily occurs. At $575^{\circ} \mathrm{C}$, squeeze casting caused a sharp increase in the dislocation density of the AZ91D magnesium alloy, which contributed to the occurrence of dynamic recrystallization. Then the squeeze force broke the dendrites, which increased the nucleation and limited the growth of the grains. The newly formed dynamic recrystallized grains were in a state of continuous deformation, and the dislocation density accumulated in the center of grain, which led to repeat dynamic recrystallization. Finally, the alloy softening caused by dynamic recrystallization succumbed to hardening caused by squeeze deformation, and the dynamic recrystallization was incomplete. Therefore, the grain size of the as-squeezed magnesium alloy was significantly finer than the as-cast magnesium alloy. The $\mathrm{Mg}_{17} \mathrm{Al}_{12}$ phase at the grain boundary was redissolved in the matrix after $\mathrm{T} 4$ treatment, the matrix grain was further refined as the recrystallization continued, and then the $\mathrm{Mg}_{17} \mathrm{Al}_{12}$ phase nucleated heterogenously on the solid phase particle, and secondary precipitates formed continuously toward the crystal ${ }^{[10]}$. The interfacial energy between the matrix and secondary precipitates can resist the secondary precipitation of $\mathrm{Mg}_{17} \mathrm{Al}_{12}$, resulting in a decrease in the density of the secondary precipitates ${ }^{[11]}$. After T6 treatment, the lamellar secondary precipitation of $\mathrm{Mg}_{17} \mathrm{Al}_{12}$ phase precipitated further until the whole grain was filled and then gradually spheroidized. With the increase of aging time, the size of matrix grain and secondary precipitates further decreased. Finally, the recrystallized grains formed the equiaxed grains without distortion.

\subsection{Mechanical properties and fracture mechanism}

The stress and strain curves of AZ91D magnesium alloy with different semi-solid squeeze temperatures are shown in Fig. 8. According to the tensile stress-strain curves, the strength and elongation of the alloys show an obvious increase after semi- 

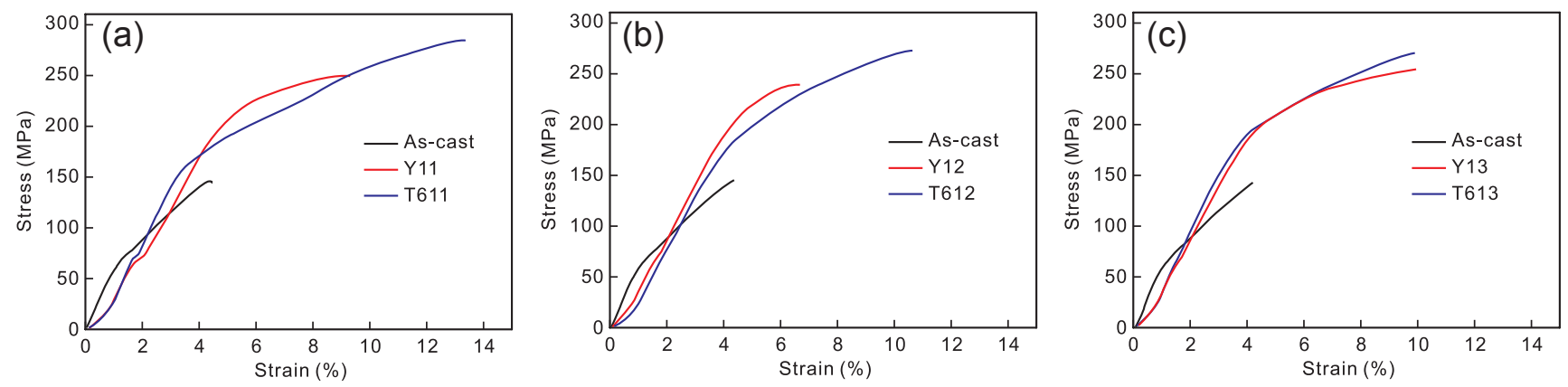

Fig. 8: Stress and strain curves of AZ91D with different semi-solid squeeze temperature: (a) $575^{\circ} \mathrm{C}$; (b) $585^{\circ} \mathrm{C}$; (c) $595^{\circ} \mathrm{C}$
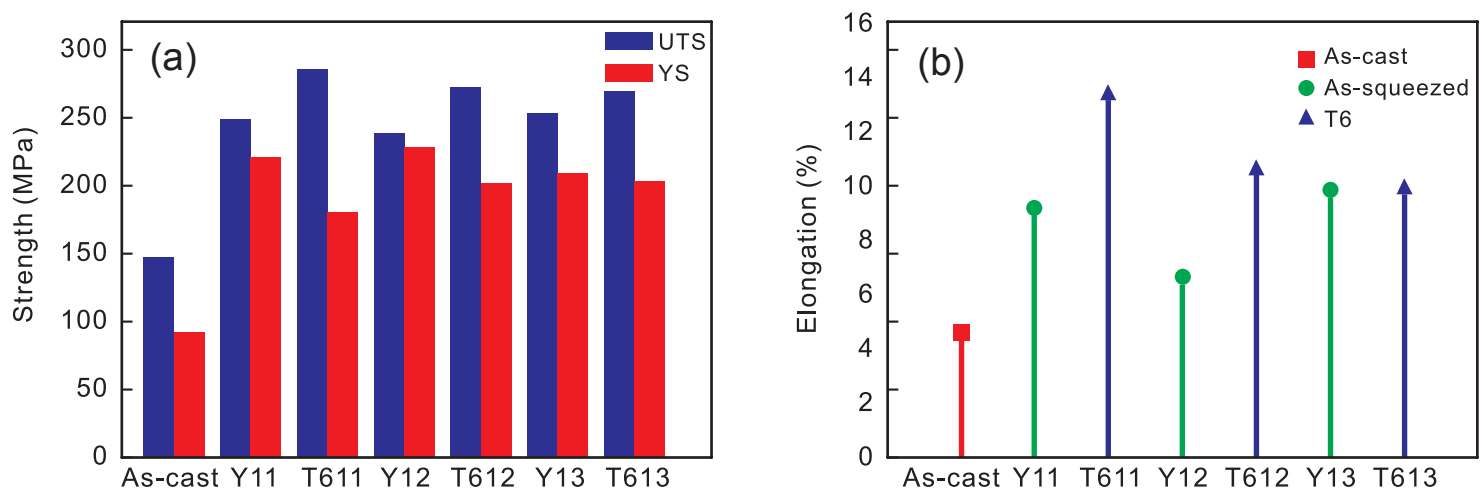

Fig. 9: Strength (a) and elongation (b) of AZ91D in different states

solid squeeze, and further increase after T6 treatment. Figure 9 shows the strength and elongation of AZ91D in different states. At $575{ }^{\circ} \mathrm{C}$ squeeze temperature, after T6 treatment, the ultimate tensile strength reached the highest of $285 \mathrm{MPa}$, the elongation reached its maximum of $13.36 \%$, but the yield strength reached the minimum of $180 \mathrm{MPa}$. The ultimate tensile strength and elongation of all the semi-solid squeezed AZ91D magnesium alloys were improved by T6 treatment. But, T6 heat treatment decreased the yield strength of all the semi-solid alloys. This is because $\mathrm{Mg}_{17} \mathrm{Al}_{12}$ phase acts as a eutectic structure, its lamellar secondary precipitates are beneficial to the strength of the alloy, and its point-like secondary precipitates are beneficial to the plasticity of the alloy but not conducive to yield strength ${ }^{[12]}$, so the alternating lamellar and point-like secondary precipitates combined to improve the strength and plasticity of the alloy ${ }^{[13]}$.

Figure 10 shows the hardness of AZ91D magnesium alloy samples in different states at different squeeze temperatures. After semi-solid squeeze casting, the hardness of AZ91D showed a significant increase, but decreased after T4 treatment, and then increased again after T6 treatment, even higher than that of the as-squeezed. At $595{ }^{\circ} \mathrm{C}$ squeeze temperature, the hardness of AZ91D reached the maximum (106.8 HV) after T6 treatment. After T4 treatment, $2 \mathrm{~L}-\mathrm{Mg}_{17} \mathrm{Al}_{12}$ phases were unevenly distributed, which decreased the hardness. In the case of $\mathrm{T} 6$ treatment, $2 \mathrm{~L}-\mathrm{Mg}_{17} \mathrm{Al}_{12}$ spread across the whole grain, gradually becoming spherical ${ }^{[7]}$. The alternate distribution of lamellar and point-like secondary precipitates resulted in a significantly increased hardness of AZ91D magnesium alloy.

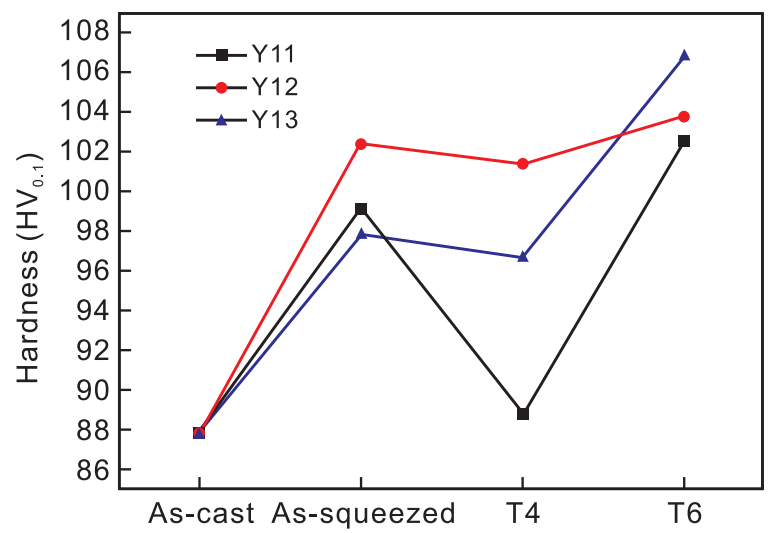

Fig. 10: Hardness of AZ91D in different states

Figure 11 shows the SEM images of the fracture surface of AZ91D magnesium alloy. According to Fig. 11(a), the fracture morphology of as-cast AZ91D shows a typical inter-granular fracture, with coarse dimples observed. Figures 11(b)-(d) show that the fracture surface of semi-solid squeezed AZ91D has plenty of dimples, but with significantly reduced dimple size with the increase of squeeze temperature. Figures 11(e)-(g) show the dimples further increase in number and decrease in size after T6 heat treatment. Furthermore, a number of tiny fracture surfaces of secondary precipitates of $\mathrm{Mg}_{17} \mathrm{Al}_{12}$ present near the dimples ${ }^{[14]}$. The implementation of suitable heat treatment promoted the tensile fracture morphology to change from inter-granular fracture to dimple fracture, which increased the strength and ductility of the alloy ${ }^{[15]}$. 

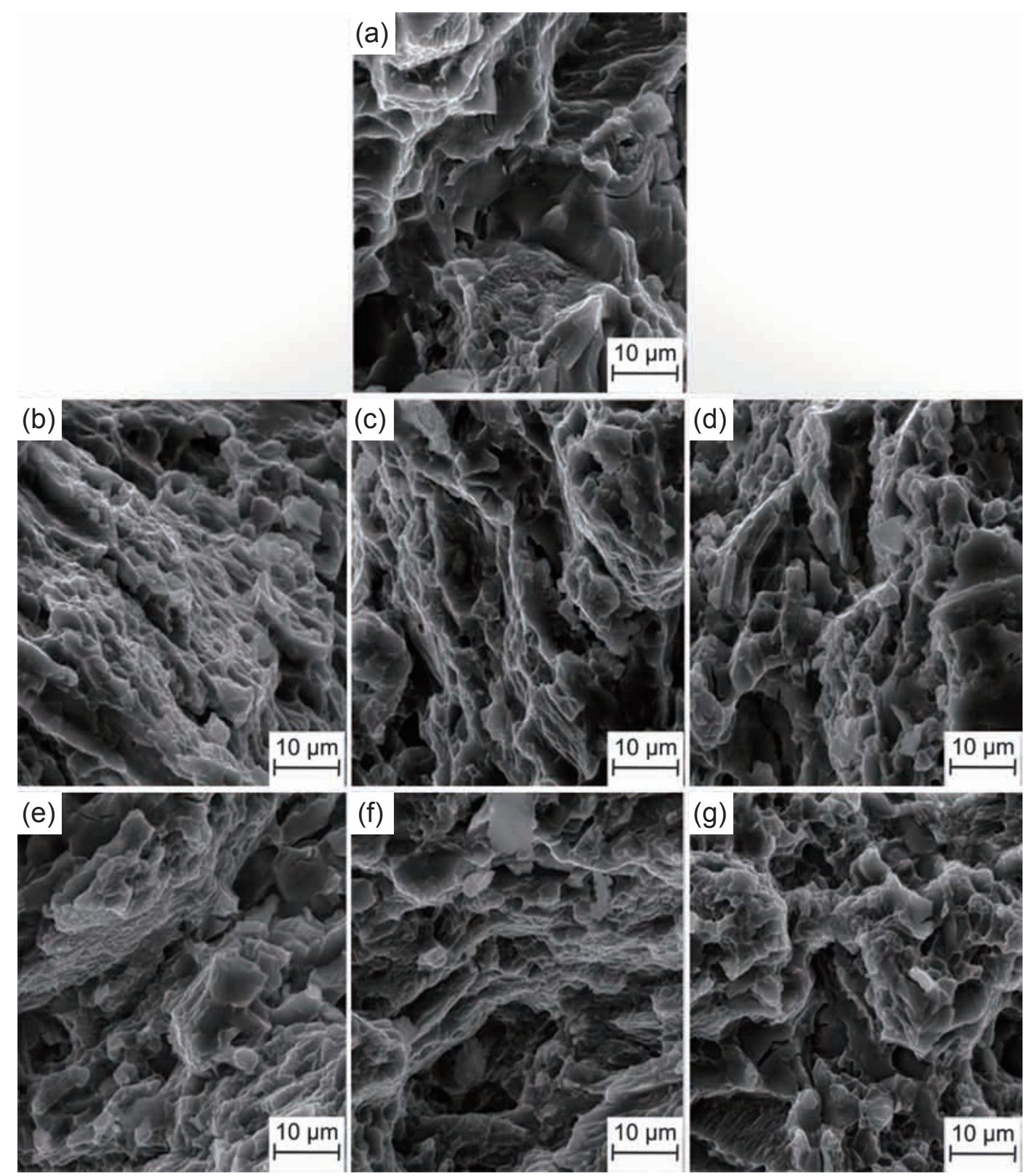

Fig. 11: SEM images of fracture surface of AZ91D: (a) as-cast; (b) Y11; (c) Y12; (d) Y13; (e) T611; (f) T612; (g) T613

\section{Conclusions}

In the present work, the microstructure and properties of semisolid squeezed AZ91D were investigated before and after heat treatment. The main conclusions obtained are as follows:

(1) In the microstructure of as-cast AZ91D, the island-like second phases $\mathrm{Mg}_{17} \mathrm{Al}_{12}$ at the grain boundary are surrounded by lamellar $\mathrm{Mg}_{17} \mathrm{Al}_{12}$. After the semi-solid squeeze casting, the point-like precipitates of $\mathrm{Mg}_{17} \mathrm{Al}_{12}$ are uniformly distributed at the grain boundaries. After T4 treatment, the $\mathrm{Mg}_{17} \mathrm{Al}_{12}$ phases at the grain boundaries are dissolved in the $\mathrm{Mg}$ matrix and secondarily precipitate toward the interior of grains from near the grain boundaries. After T6 treatment, the secondary precipitated $\mathrm{Mg}_{17} \mathrm{Al}_{12}$ phases spread across the whole grain.

(2) After semi-solid squeeze casting, the grain size decreases significantly. With the squeeze temperature increases, the grain size increases continuously. At the same squeeze temperature, the grain size continuously decreases with the heat treatment. When the squeeze temperature is $575^{\circ} \mathrm{C}$, the average grain size after T6 heat treatment is $17.01 \mu \mathrm{m}$, and the size of the second phase is $0.50 \mu \mathrm{m}$, and the volume fraction of the second phase is $23.05 \%$.

(3) T6 treatment increases the ultimate tensile strength and elongation of the semi-solid squeeze cast AZ91D alloy. The alternate distribution of lamellar and point-like secondary precipitates improves the hardness and plasticity of the alloy. After $575{ }^{\circ} \mathrm{C}$ squeeze casting and T6 treatment, the ultimate tensile strength is $285 \mathrm{MPa}$, the elongation is $13.36 \%$, and the yield strength is $180 \mathrm{MPa}$. After $595{ }^{\circ} \mathrm{C}$ squeeze casting and T6 treatment, the maximum hardness of AZ91D reaches $106.8 \mathrm{HV}$.

(4) After semi-solid squeeze casting and T6 treatment, the tensile fracture of the alloy shows a typical ductile fracture. 


\section{References}

[1] Bahrami A, Razaghian A, Emamy M, et al. Microstructure and tensile properties of $\mathrm{Al}-15 \mathrm{wt} . \% \mathrm{Mg}_{2} \mathrm{Si}$ composite after hot extrusion and heat treatment. Key Engineering Materials, 2011,1213(943): 1171-1176.

[2] Wang Xiaojun, Hu Xiaoshi, Nie Kaibo, et al. Hot extrusion of $\mathrm{SiC}_{\mathrm{p}} / \mathrm{AZ91} \mathrm{Mg}$ matrix composites. Transactions of Nonferrous Metals Society of China, 2012, 22(8): 1912-1917.

[3] Chen Tian, Xie Zhiwen, Luo Zhuangzhu, et al. Microstructure evolution and tensile mechanical properties of thixoformed AZ61 magnesium alloy prepared by squeeze casting. Transactions of Nonferrous Metals Society of China, 2014, 24(11): 3421-3428.

[4] Kleiner S, Beffort O, Wahlen A, et al. Microstructure and mechanical properties of squeeze cast and semi-solid cast Mg-Al alloys. Journal of Light Metals, 2002, 2(4): 277-280.

[5] Tang Zhongxue, Li Yuandong, Hao Yuan. Effects of aging treatment on microstructures and mechanical properties of thixoformed AZ91D magnesium alloy. Hot Working Technology, 2005, 3: 4-7. (In Chinese)

[6] Li Yuandong, Tang Zhongxue, Hao Yuan, et al. Investigation of solid-solution and aging treatment of thixoformed alloy AZ91D. Journal of Lanzhou University of Technology, 2005, 31(5): 1518. (In Chinese)

[7] Sun Xuefei, Wang Cuiju, Deng Kunkun, et al. Aging behavior of AZ91 matrix influenced by $5 \mu \mathrm{m} \mathrm{SiCp:} \mathrm{Investigation} \mathrm{on} \mathrm{the}$ microstructure and mechanical properties. Journal of Alloys and Compounds, 2017, 727: 1263-1272.

[8] Qi Yesi, Chen Tijun, Li Yuanning, et al. Effects of solution treatment time on microstructure and mechanical properties of thixoformed AZ63 magnesium alloy. Special Casting \& Nonferrous Alloys, 2013, 33(12): 1127-1131. (In Chinese)
[9] Dong Qing, Luo Zhe, Zhu Hong, et al. Basal-plane stackingfault energies of $\mathrm{Mg}$ alloys: A first-principles study of metallic alloying effects. Journal of Materials Science and Technology, 2018, 34(10): 1773-1780.

[10] Zhang Li, Deng Kunkun. Microstructures and mechanical properties of $\mathrm{SiC}_{\mathrm{p}} / \mathrm{Mg}-x \mathrm{Al}-2 \mathrm{Ca}$ composites collectively influenced by $\mathrm{SiC}_{\mathrm{p}}$ and $\mathrm{Al}$ content. Materials Science and Engineering: A, 2018, 725: 510-521.

[11] Peng Guosheng, Chen Kanghua, Chen Songyi, et al. Evolution of the second phase particles during the heating-up process of solution treatment of Al-Zn-Mg-Cu alloy. Materials Science \& Engineering A, 2015, 641: 237-241.

[12] Sun Xuefei, Wang Cuiju, Deng Kunkun, et al. High strength $\mathrm{SiC}_{\mathrm{p}} / \mathrm{AZ91}$ composite assisted by dynamic precipitated $\mathrm{Mg}_{17} \mathrm{Al}_{12}$ phase. Journal of Alloys and Compounds, 2018, 732 328-335.

[13] Wang Huiyuan, Zhang Enbo, Nan Xiaolong, et al. A comparison of microstructure and mechanical properties of $\mathrm{Mg}-9 \mathrm{Al}-1 \mathrm{Zn}$ sheets rolled from as-cast, cast-rolling and asextruded alloys. Materials \& Design, 2016, 89: 167-172.

[14] Wang Xiaojun, Wu Kun, Huang Wenxian, et al. Study on fracture behavior of particulate reinforced magnesium matrix composite using in situ SEM. Composites Science and Technology, 2007, 67(11-12): 2253-2260.

[15] Zhao Pin, Shen Huanxiang, Zhao Ensheng. Decomposition products and properties of supercooled $\beta$ phase of $Z n-27 A 1-$ 2.7Cu-0.03Mg-0.5Mn alloy. Non-ferrous Metal, 2004, 56(2): 1-7. (In Chinese) 